\title{
Las cláusulas europeas de los nuevos Estatutos de Autonomía en la perspectiva del Tratado de Lisboa
}

\author{
David Ordóñez Solís \\ Magistrado, doctor en Derecho y miembro de la Red de Expertos en \\ Derecho de la Unión Europea del Consejo General del Poder Judicial
}

\begin{abstract}
SUMARIO: I. INTRODUGGIÓN II. PRIMERA PARTE. LA PARTICIPACIÓN REGIONAL EN LA UNIÓN EUROPEA A PARTIR DEL TRATADO DE LISBOA 1. Los principios de gobernanza y de subsidiariedad para la implicación de las regiones en la Unión Europea 2. El reforzamiento del Comité de las Regiones 3. La participación de los Parlamentos regionales en la Unión Europea 4. El estatuto de las regiones ante el Tribunal de Justicia de la Unión Europea III. SEGUNDA PARTE. LAS CLÁUSULAS EUROPEAS DE LOS ESTATUTOS DE LAS COMUNIDADES ESPAÑOLAS 1. La identidad y el compromiso de las Comunidades Autónomas españolas en clave europea 2. Los nuevos derechos fundamentales estatutarios en el contexto europeo 3. Las cláusulas de participación de las Comunidades Autónomas en las instituciones de la Unión Europea. A. Las Comunidades Autónomas españolas y el Consejo de la Unión Europea: participación interna, representación en el Consejo y las Delegaciones autonómicas ante la Unión Europea. B. Las Comunidades Autónomas españolas, la Comisión Europea y el Comité de las Regiones. C. Los Parlamentos autonómicos españoles y el Parlamento Europeo.D. Las Comunidades Autónomas españolas ante el Tribunal de Justicia de la Unión Europea 4. Las cláusulas de participación autonómica en la ejecución del Derecho de la Unión Europea: transposición de directivas y gestión de fondos comunitarios a) La competencia de la ejecución del Derecho de la Unión Europea b) Las directivas europeas, la legislación básica estatal y la legislación autonómica c) La gestión de los fondos europeos por las Comunidades Autónomas. IV. CONCLUSIÓN
\end{abstract}

RESUMEN:

El proceso de reforma de los Estatutos de autonomía en 2006 y 2007 ha sido paralelo a la renovación constitucional de la Unión Europea llevada a cabo, finalmente, con la entrada en vigor del Tratado de Lisboa el 1 de diciembre de 2009. La participación de las regiones en la Unión Europea se ha visto reforza- 
da con el nuevo Tratado europeo a pesar de que los Estados miembros siguen teniendo el protagonismo institucional. Al mismo tiempo, los Estatutos de autonomía que hasta ahora se han remozado han codificado, sin mayores objeciones políticas ni judiciales, las normas y de los convenios adoptados hasta ahora y que afectan a la participación interna y externa de las Comunidades Autónomas, y que suponen la implicación regional tanto en la fase de adopción como en la fase de ejecución del Derecho de la Unión Europea.

Palabras clave:

Región, Tratado de Lisboa, Unión Europea, Sistema Institucional Europeo, Descentralización

\section{ABSTRACT:}

The process of reform of the Spanish Regions in 2006 and 2007 has been parallel to the constitucional developments in the European Union, concluded with the entry in force of the Lisbon Treaty on $1^{\text {st }}$ december 2009. The regional participation in the European Union has been reinforced by the new European Treaty, notwithstanding the pivotal role of Member States in the institutional framework. At the same time and without political nor judicial complains, the Autonomous Fundamental Laws that have been reformed until now codify the legislative and conventional practices regarding the internal and the European regional participation. These new constitutive provisions strengthen the implication of Spanish Regions in the European decision process making and in the enforcement of the Law of the European Union.

Key words:

Region, Treaty of Lisbon, European Union, European Institutional System, Devolution

\section{INTRODUGGIÓN}

El 1 de diciembre de 2009 entró en vigor el Tratado de Lisboa con lo que culminó un largo proceso de constitucionalización de la Unión Europea que se había iniciado al día siguiente de la firma en 2001 del Tratado de Niza. Inicialmente la reforma constitucional se recogió en el malogrado Proyecto de Tratado de Constitución europea de 29 de octubre de 2004 pero los desastres referendarios en Francia, Países Bajos e Irlanda obligaron a maquillar las re- 
formas firmadas en Roma con el Tratado de Lisboa de 13 de diciembre de $2007^{1}$.

El Tratado de la Unión Europea y el Tratado de Funcionamiento de la Unión Europea, tal como han sido modificados por el Tratado de Lisboa, no son especialmente innovadores en cuanto se refiere a la participación de las regiones en la integración europea, pero no hay duda de que las regiones en Europa han adquirido un particular estatuto que si bien no es comparable con el de los Estados miembros dista de ser, como ocurría en la práctica en los Tratados fundacionales de las Comunidades Europeas de los años 50, una mera referencia geográfica. Algunos de los principales Estados de la Unión Europea cuentan con sistemas federales o regionales particularmente sólidos, como es el caso de Alemania, Bélgica, Austria, España o Italia; algunos han conferido autonomía especial a determinadas regiones como las Islas Azores en Portugal o las Islas Åland en Finlandia; y, en fin, otros países tradicionalmente centralistas, como pudiera ser el caso del Reino Unido o Francia, han propiciado, bien es verdad que paulatinamente, una cierta descentralización territorial.

El marco institucional europeo permite, en cierta medida, una participación de las regiones, hasta el punto de contar con un Comité de las Regiones y los principios que inspiran el funcionamiento de la Unión Europea alientan la implicación en la adopción de decisiones y en su ejecución a los distintos niveles de gobierno de los Estados miembros, incluidos los regionales y los locales.

Casi al mismo tiempo que se constitucionalizaba la Unión Europea, en España se ha llevado a cabo a partir de 2005 un proceso, que aún no ha concluido, de renovación de los Estatutos de autonomía en el que, de manera especial y sin particulares controversias a diferencia de otras cuestión especialmente conflictivas, se ha tenido en cuenta por primera vez y de modo sistemático la participación de las Comunidades Autónomas en la Unión Europea.

Los Estatutos de Autonomía renovados en 2006 y 2007 introducen unas cláusulas europeas que, en líneas generales, suponen la estatutarización de los avances habido hasta ahora en la participación de las Comunidades Autónomas en la Unión Europea y cuya constitucionalidad ha sido corroborada por la sen-

\footnotetext{
${ }^{1}$ David ORDÓÑEZ SOLÍS, "Lo que se salvó en Lisboa y su significado en la pequeña historia constitucional de la Unión Europea", Cuadernos Europeos de Deusto n ${ }^{\circ}$ 40/2009, Bilbao, pp. $109-148$.
} 
tencia $n^{\circ} 31 / 2010$, de 28 de junio, sobre el Estatuto catalán². Es importante subrayar que, a diferencia de otros aspectos sumamente controvertidos como el uso de término nación, el blindaje de las competencias asumidas por Cataluña o la configuración del Poder judicial en el Estatuto, la impugnación judicial de las cláusulas europeas había sido sólo incidental y más bien se relacionaba con los aspectos sustantivos internos. Lo relevante es que el Tribunal Constitucional, prácticamente cohesionado y sin discrepancias significativas en los votos particulares, no apreció inconstitucionalidad alguna en la redacción de las cláusulas europeas del nuevo Estatuto catalán, apuntando solo en algunos supuestos puntualizaciones esencialmente técnicas. No obstante, en su sentencia el Tribunal Constitucional repite: «la participación de la Generalitat, prevista en el Estatuto, en los asuntos relacionados con la Unión Europea que afecten a las competencias o intereses de Cataluña ha de tener lugar en los concretos términos que establezca la legislación del Estado» (FJ 122).

El contraste entre el estatuto regional que resulta de la reforma del Tratado de Lisboa y las cláusulas estatutarias autonómicas españolas puede servir de referencia sobre lo que son y lo que pueden hacer las regiones, en particular las Comunidades Autónomas españolas, en la Unión Europea.

Así pues, me propongo examinar la dimensión regional de ambos procesos: por una parte, la implicación regional en la Unión Europea impulsada en Lisboa y, por otra, la estatutarización de la participación de las Comunidades Autónomas españolas en Europa. En una primera parte pretendo exponer cuál es, a raíz del Tratado de Lisboa, el espacio que ofrece la actual Unión Europea a la participación de las regiones; y, en la segunda parte, procuro analizar, tal como

\footnotetext{
${ }^{2}$ El Tribunal Constitucional se ha pronunciado sobre la reforma estatutaria valenciana, desestimando los recursos formulados por el Gobierno aragonés, en la sentencia $n^{\circ}$ 247/2007, de 12 de diciembre (Pleno, ponente: Pérez Vera) y, por el Gobierno castellano-manchego, en la sentencia $n^{\circ}$ 249/2007, de 13 de diciembre (Pleno, ponente: Delgado Barrio) en relación con el reconocimiento del 'derecho de redistribución de los sobrantes de agua de cuencas excedentarias atendiendo a criterios de sostenibilidad de acuerdo con la Constitución y la legislación estatal'. La sentencia n ${ }^{\circ} 31 / 2010$, de 28 de junio (Pleno, ponente: Casas Baamonde) estima en parte el recurso de inconstitucionalidad formulado por el Partido Popular contra el nuevo Estatuto de Autonomía para Cataluña; la doctrina contenida en esta sentencia se ha aplicado para desestimar en dos sentencias de 8 de septiembre y una de 9 de septiembre de 2010 los recursos de inconstitucionalidad las sentencias $n^{\circ} 46 / 2010$ y n $^{\circ} 47 / 2010$, de 8 de septiembre, $n^{\circ} 48 / 2010$, de 9 de septiembre, y n ${ }^{\circ} 49 / 2010$, de 29 de septiembre de 2010 los recursos interpuestos por el los Gobiernos de Aragón, Illes Balears y Valencia contra el Estatuto catalán que, en sustancia, remiten a la interpretación de la sentencia Aragón, Illes Balears, Valencia y Murcia nº 31/2010.
} 
se recogen en sus nuevos Estatutos, los procedimientos de participación de las Comunidades Autónomas españolas en los asuntos europeos.

\section{PRIMERA PARTE. LA PARTICIPACIÓN REGIONAL EN LA UNIÓN EUROPEA A PARTIR DEL TRATADO DE LISBOA}

El Tratado de Lisboa constituye un paso más, probablemente el tercero más importante de la integración europea, desde que se fundaran las Comunidades Europeas en los años $50 \mathrm{y}$ desde que se diera un giro radical al proyecto comunitario europeo con la firma del Tratado de Maastricht en 1992. Ahora bien, desde el punto de vista de la participación regional en la Unión Europea el Tratado de Lisboa solo aporta pequeñas novedades aunque, ciertamente, mantiene el tradicional sistema institucional de creación y aplicación del Derecho de la Unión Europea en el que paulatinamente se ha propiciado la participación regional.

Las novedades más importantes del Tratado de Lisboa que podrían afectar directa o indirectamente a las regiones giran en torno a la consolidación de los principios de gobernanza y de subsidiariedad, al fortalecimiento del Comité de las Regiones y a la nueva dimensión aportada a los Parlamentos nacionales, incluidos los Parlamentos regionales, en el procedimiento de adopción de decisiones. Estos avances, sin embargo, no pueden minimizar las reticencias que en determinados ámbitos, en particular en el Tribunal de Justicia de la Unión Europea, suscita un fortalecimiento del estatuto de las regiones europeas.

\section{Los principios de gobernanza y de subsidiariedad para la implicación de las regiones en la Unión Europea}

El Tratado de Funcionamiento de la Unión Europea consagra en su artículo 15 (antiguo artículo 255 Tratado CE) el principio de gobernanza en estos términos: «A fin de fomentar una buena gobernanza y de garantizar la participación de la sociedad civil, las instituciones, órganos y organismos de la Unión actuarán con el mayor respeto posible al principio de apertura».

Con la consagración de este principio de gobernanza se dulcifica, de algún modo, la aplicación de la tradicional autonomía institucional y procedimental que se reconoce a los Estados miembros en la Unión Europea. En efecto, tal como ha reiterado el Tribunal de Justicia, es indiferente para el Derecho de la Unión Europea la organización interna de cada Estado miembro, lo que, en definitiva, resulta relevante es la participación o la relación de cada Estado miem- 
bro con las instituciones europeas de acuerdo con su propio sistema constitucional interno.

Esto explica que, por ejemplo, un principio tan característicamente federal como el de subsidiariedad se haya revestido y adaptado a cualquier interpretación sea o no federal o regional. Y lo mismo ocurre con la formulación del principio de gobernanza como implicación de los distintos niveles de gobierno de la Unión Europea.

Ahora bien, la proclamación de los dos principios, de gobernanza y de subsidiariedad, y la existencia de procedimientos específicos para hacer valer el principio de subsidiariedad, contribuirán, sin lugar a dudas, a impulsar, aun cuando sea limitadamente, la participación regional en la Unión Europea.

El Protocolo sobre la aplicación de los principios de subsidiariedad y proporcionalidad prevé que la Comisión Europea, antes de proponer un acto legislativo, proceda a amplias consultas y «ten[ga] en cuenta, cuando proceda, la dimensión regional y local de las acciones previstas». Y también este mismo Protocolo, perfeccionado en Lisboa, exige la motivación de las propuestas legislativas «en relación con los principios de subsidiariedad y de proporcionalidad» lo que significa, en particular, que se incluyan «elementos que permitan evaluar el impacto financiero y, cuando se trate de una directiva, sus efectos en la normativa que han de desarrollar los Estados miembros, incluida, cuando proceda, la legislación regional».

\section{El reforzamiento del Comité de las Regiones}

El Tratado de Lisboa supone el impulso más importante recibido por el Comité de las Regiones desde su constitución en 1994. Por una parte, destaca la amplia obligación de las instituciones, el Consejo y la Comisión, de consultar al Comité de las Regiones en determinadas materias así como la ampliación de su derecho a formular dictámenes por iniciativa propia o cuando las instituciones consulten al Comité Económico y Social y en ese caso «cuando [el Comité de las Regiones] estime que hay intereses regionales específicos en juego» (artículo 307 Tratado FUE). Y, por otra parte, el Protocolo sobre la aplicación de los principios de subsidiariedad y proporcionalidad abre nuevos horizontes al Comité de las Regiones.

Desde el punto de vista institucional, las regiones reciben un importante impulso en el Tratado de Funcionamiento de la Unión Europea al reforzar el Comité de las Regiones y al configurar algunas políticas de la Unión, tal como se 
había establecido en reformas previas (política agrícola, política regional, política social y medioambiente) y en los términos en que se introduce en nuevos ámbitos de actuación complementaria (salud, educación, cultura y turismo).

El Comité de las Regiones, aun cuando no ha podido llevar a cabo hasta ahora más que actuaciones simbólicas, se ha constituido probablemente en el foro más importante del movimiento regional europeo y es el ámbito institucional más apropiado para la representación de los intereses locales, especialmente postergados en la Unión Europea.

El Comité de las Regiones podrá adquirir una nueva dimensión y podrá alcanzar una clara visibilidad en el ejercicio de su nueva legitimación ante el Tribunal de Justicia de la Unión Europea con el fin de salvaguardar sus prerrogativas como órgano de representación regional y local (artículo 263.3 Tratado FUE) y para controlar la aplicación del principio de subsidiariedad. En este último caso, el Protocolo sobre la subsidiariedad otorga legitimación expresa al Comité de las Regiones para interponer ante el Tribunal de Justicia recursos contra actos legislativos para cuya adopción el Tratado de Funcionamiento de la Unión Europea requiera su consulta.

\section{La participación de los Parlamentos regionales en la Unión Europea}

Probablemente una de las contribuciones más originales del Tratado de Lisboa haya sido la implicación decidida de los Parlamentos nacionales en la integración europea. De hecho, el artículo 12 TUE dispone: «Los Parlamentos nacionales contribuirán activamente al buen funcionamiento de la Unión». La participación de los Parlamentos nacionales, incluidos los regionales, se prevé a través de dos Protocolos al Tratado constitutivo: el Protocolo ${ }^{\circ} 1$ sobre el cometido de los Parlamentos nacionales en la Unión Europea establece mecanismos de colaboración, propuesta y control en los asuntos europeos. Precisamente, una de las competencias que se atribuye a los parlamentos nacionales es el control del cumplimiento de la subsidiariedad y de la proporcionalidad hasta el punto de que en el Protocolo $\mathrm{n}^{\circ} 2$ sobre la aplicación de los principios de subsidiariedad y proporcionalidad hace referencia expresa a los Parlamentos regionales.

El Protocolo $\mathrm{n}^{\circ} 1$ sobre los Parlamentos nacionales pretende, en especial, «impulsar una mayor participación de los Parlamentos nacionales en las actividades de la Unión Europea e incrementar su capacidad para manifestar su opinión sobre los proyectos de actos legislativos de la Unión Europea y otros asuntos que consideren de especial interés». Se trata de una participación abierta 
que, no obstante, queda a la discreción y a la voluntad y disposición de cada Parlamento el ejercicio de su capacidad de influencia en el proceso de adopción de decisiones en la Unión europea.

El Protocolo $\mathrm{n}^{\mathrm{o}} 2$ es un mecanismo de control del mismo proceso de adopción de decisiones en la aplicación de la subsidiariedad y de la proporcionalidad. Este procedimiento confiere a los Parlamentos nacionales un poder que expresa en estos términos su artículo 6: «Todo Parlamento nacional o toda cámara de uno de estos Parlamentos podrá, en un plazo de ocho semanas a partir de la fecha de transmisión de un proyecto de acto legislativo en las lenguas oficiales de la Unión, dirigir a los Presidentes del Parlamento Europeo, del Consejo y de la Comisión un dictamen motivado que exponga las razones por las que considera que el proyecto no se ajusta al principio de subsidiariedad. Incumbirá a cada Parlamento nacional o a cada cámara de un Parlamento nacional consultar, cuando proceda, a los Parlamentos regionales que posean competencias legislativas».

La fuerza del dictamen de los Parlamentos nacionales sólo se adquiere cuando se hayan pronunciado en el mismo sentido un tercio o un cuarto si se trata de cuestiones relativas al espacio de libertad, seguridad y justicia del total de los mismos y sus efectos consisten en que el proyecto vuelva a ser considerado por la Comisión Europea; asimismo, en caso de que llegue al Consejo cabe el rechazo de la propuesta por el $55 \%$ de los miembros o por la mayoría del Parlamento Europeo; en fin, los Parlamentos nacionales pueden, a través de sus Gobiernos, formular recursos de anulación fundados en la vulneración de la subsidiariedad y de la proporcionalidad. En este sentido y tal como ha puesto de manifiesto el Tribunal Constitucional Federal alemán en su sentencia de 30 de junio de 2009, «la eficacia de este mecanismo dependerá de la capacidad organizativa de adaptarse con el fin de obtener ventajas útiles en un breve plazo de ocho semanas» ${ }^{3}$.

\section{El estatuto de las regiones ante el Tribunal de Justicia de la Unión Europea}

Los avances 'regionales' antes referidos no impiden constatar las reticencias del Tribunal de Justicia a otorgar un status procesal privilegiado a las Regiones:

\footnotetext{
3 Tribunal Constitucional Federal Alemán, sentencia de 30 de junio de 2009 (2 BvE 2/08 2 BvE 5/08 - 2 BvR 1010/08 - 2 BvR 1022/08 - 2 BvR 1259/08 - 2 BvR 182/09) (Tratado de Lisboa).
} 
tanto en lo que se refiere a la legitimación pasiva en los recursos por incumplimiento como a la legitimación activa en los recursos de anulación, prefiriendo en ambos casos considerar en exclusiva a los respectivos Estados miembros.

El Tribunal de Justicia sólo admite que los recursos por incumplimiento, habitualmente interpuestos por la Comisión Europea, se dirijan contra los Estados miembros, aunque esto no le impide, al analizar el cumplimiento del Estado miembro en cuestión, señalar si el origen de la infracción está en una determinada Región ${ }^{4}$.

Del mismo modo, el Tribunal de Justicia ha desautorizado la mayor comprensión del Tribunal de Primera Instancia con la legitimación de las Regiones para impugnar decisiones de la Comisión Europea relativa a la gestión de fondos europeos. Tal es el caso de dos sentencias del Tribunal de Justicia relativas a las correcciones financieras del FEDER realizadas por la Comisión y recurridas judicialmente por la región de Sicilia: mientras que el Tribunal de Primera Instancia admitió y desestimó los recursos, el Tribunal de Justicia corrigió la interpretación de instancia e inadmitió ambos recursos por falta de legitimación activa de Sicilia ${ }^{5}$.

En estas sentencias el Tribunal comunitario recuerda que el recurso de anulación de una entidad regional o local no puede asimilarse al recurso de un Estado miembro, toda vez que el concepto de Estado miembro «únicamente va destinado a las autoridades gubernativas de los Estados miembros. Dicho concepto no puede ampliarse a los Gobiernos de regiones o entidades de ámbito inferior al Estado sin conculcar el equilibrio institucional previsto por el Tratado» (apartado 21).

\footnotetext{
${ }^{4}$ En la sentencia de 7 de mayo de 2009, Comisión / España, relativa a la designación de las autoridades competentes para determinadas demarcaciones hidrográficas, (C-516/07, Rec. p. I-), el Tribunal de Justicia concluye: «De todas las consideraciones anteriores resulta que el Reino de España ha incumplido las obligaciones que le incumben en virtud del artículo 3, apartados 2, 7 y 8, de la Directiva 2000/60, al no haber designado las autoridades competentes para aplicar las disposiciones de dicha Directiva por lo que respecta a las Comunidades Autónomas de Galicia, del País Vasco, de Andalucía, de Baleares y de Canarias» (apartado 64).

${ }^{5}$ TJCE (GS), sentencia de 2 de mayo de 2006, Regione Siciliana / Comisión (ayuda del FEDER para la autopista Mesina-Palermo) (C-417/04 P, Rec. p. I-3881) y TJCE, sentencia de 22 de marzo de 2007, Regione Siciliana / Comisión (ayuda del FEDER para el proyecto de embalse en el río Gibbesi) (C-15/06 P, Rec. p. I-2591).
} 
Y a tal efecto, el Tribunal de Justicia explica que, si bien Sicilia había sido designada autoridad responsable de la realización del proyecto FEDER, «sin embargo, ninguno de los elementos que obran en autos permite concluir que la recurrente resultó directamente afectada, a efectos del artículo $230 \mathrm{CE}$, párrafo cuarto, en dicha condición. A este respecto, es preciso destacar que la función de autoridad responsable de la realización del proyecto, mencionada en el anexo de la Decisión de concesión, no implicaba que la propia recurrente fuera titular del derecho a la ayuda» (apartado 30).

Y también en otros ámbitos menos decisivos, el Tribunal de Justicia se ha negado a igualar, a efectos del reconocimiento de derechos de eurofuncionarios, la relación entre el Estado central, como Estado miembro, y una Región, en este caso una Comunidad Autónoma. Los litigios que enjuiciaron los Tribunales comunitarios se referían a ventajas salariales de aquellos eurofuncionarios que previamente habían estado destacados en Bruselas como empleados de las Regiones europeas y que pretendían que se equiparase su situación de expatriación a la vinculación con la Representación Permanente ante la Unión Europea.

En estos supuestos las instituciones europeas denegaron las solicitudes de indemnización por expatriación presentadas por varios eurofuncionarios que previamente habían desempeñado su trabajo en las oficinas, sociedades o patronatos de las Comunidades Autónomas en Bruselas dado que para el Tribunal de Justicia sólo podía considerar en situación de expatriación a los empleados públicos que hubiesen formado parte oficialmente de la representación permanente de ese Estado ${ }^{6}$.

\footnotetext{
${ }^{6}$ Así resulta de la sentencia del Tribunal de Primera Instancia, de 13 de septiembre de 2005, Recalde Langarica / Comisión (T-283/03, Rec. p. II-1075) donde la reclamación la formulaba una persona que había trabajado en Bruselas en la sociedad Interbask, vinculada al Gobierno vasco; y de las sentencias de 25 de octubre de 2005 en asuntos muy similares: así, en el caso Salvador García / Comisión (T-205/02. Rec. p. II-1311) el recurrente había prestado servicios para Sociedad de Desarrollo de Navarra, Sodena, S.A., vinculada a la Comunidad Autónoma de Navarra; en el asunto Dedeu i Fontcuberta / Comisión (T-299/02) el recurrente había trabajado también para el Patronat Catalá pro Europa, aunque acreditó que no había residido en Bruselas en los términos previstos por la regulación de la indemnización por expatriación; en el asunto Bustamante Tello / Consejo (T-368/03, Rec. p. II-1439), el eurofuncionario había trabajado previamente en la Oficina de Murcia en Bruselas; y el asunto Salazar Brier / Comisión ( $\mathrm{T}-83 / 03)$, se trataba de un funcionario que previamente estaba vinculado al Gobierno de Canarias. La posición del Tribunal de Justicia se ofrece en las sentencias de 29 de noviembre de 2007, Salvador García / Comisión (C-7/06P, Rec. p. I-10265), Herrero Romeu / Comisión
} 


\section{SEGUNDA PARTE. LAS GLÁUSULAS EUROPEAS DE LOS ESTA- TUTOS DE LAS COMUNIDADES ESPAÑOLAS}

$\mathrm{Al}$ mismo tiempo que se ponía en marcha en España el Estado de las Autonomías se inició la negociación de la adhesión a las Comunidades Europeas. Los dos primeros Estatutos, el catalán y el vasco, se aprobaron en diciembre de 1979 y el último Estatuto publicado fue el de Castilla y León en 2003. La adhesión se solicitó en 1978 y las negociaciones se iniciaron en 1979, culminándose con la firma del Tratado de Adhesión el 12 de junio de 1985, que entró en vigor el 1 de enero de 1986.

La integración de España en Europa ha supuesto tanto un freno como un impulso del mismo proceso de descentralización española. La dinámica reticente a la implicación de las Comunidades Autónomas puede observarse en períodos muy significativos como pueden ser los tres primeros años de la adhesión de España a las Comunidades Europeas, de 1986 a 1988, en el Gobierno presidido por Felipe González, o las épocas en que los Gobiernos centrales no requerían apoyo de grupos nacionalistas, como la legislatura comprendida entre 2000 y 2004 bajo el protagonismo del Gobierno de José María Aznar; pero también en otras épocas la participación de las Comunidades Autónomas en la Unión Europea tuvo un significativo impulso cuando Gobiernos centrales de distinto sig-

(C-8/06P, Rec. p. I-10333; Salazar Brier / Comisión (C-9/06P, Rec. p. I-10357); y De Bustamante Tello / Consejo (G-10/06, Rec. p. I-10381); por ejemplo, en esta última sentencia el Tribunal de Justicia puntualiza: «Aun cuando el reparto de competencias en el plano estatal interno varía en función de la estructura institucional de cada Estado, éste debe tener la consideración, en Derecho internacional público, de sujeto con carácter unitario. A la luz de esta interpretación, se exige que el Estado esté representado, ante otros Estados y ante las organizaciones internacionales, por un sistema de representación diplomática único, que es reflejo de la unidad, en el plano internacional, del Estado de que se trate» (apartado 39); y, para concluir, el Tribunal de Justicia explica: «con carácter ilustrativo, se ha de señalar que en España, en virtud del Acuerdo sobre la Consejería para Asuntos Autonómicos en la Representación Permanente de España ante la Unión Europea y sobre la participación de las Comunidades Autónomas en los grupos de trabajo del Consejo de la Unión Europea y sobre el sistema de representación autonómica en las formaciones del Consejo de la Unión Europea, aprobado por el Gobierno español el 9 de diciembre de 2004 en el marco de la Conferencia para Asuntos con las Comunidades Europeas (aunque este Acuerdo no existiese en la época de los hechos que dieron lugar al presente litigio y, por lo tanto, no le sea aplicable), al menos dos puestos de consejero para asuntos autonómicos en dicha Representación Permanente están ocupados por funcionarios de las Comunidades Autónomas con competencias en el plano estatal interno, pero integrados en esa Representación Permanente» (apartado 49). 
no requirieron un importante apoyo nacionalista, catalán o vasco, como ocurrió con los últimos años del Gobierno de Felipe González, de 1992 a1996, el Gobierno de José Ma Aznar entre 1996 y 2000 o con los Gobiernos de José Luis Rodríguez Zapatero a partir de $2004^{7}$.

Aun cuando suponga una cierta simplificación podría analizarse la participación autonómica en Europa en torno a tres períodos: el primer período estaría marcado por la creación de las Comunidades Autónomas y por la negociación y adhesión de España a las Comunidades Europeas (1978 a 1992); el segundo período coincidiría con la consolidación de las Comunidades Autónomas y su participación en la integración europea, que toma impulso a partir de la puesta en marcha en Maastricht de la Unión Europea (de 1993 a 2006); y el tercer período se abriría en España con la renovación de los Estatutos de Autonomía a partir de 2006 que incluyen importantes cláusulas europeas y la firma y la ratificación del Tratado de Lisboa el 13 de diciembre de 2007 y en vigor desde el 1 de diciembre de 2009.

El período actual caracterizado por la renovación de los Estatutos de autonomía se inicia con el 'Proyecto de nuevo Estatuto vasco', impulsado por el presidente Ibarretxe, que fue rechazado por las Cortes Generales en enero de $2005^{8}$. En cambio, en 2006 y en 2007 se culminó el proceso de renovación de seis Estatutos autonómicos ${ }^{9}$ : el valenciano (10 de abril de 2006) ${ }^{10}$, el catalán (19

${ }^{7}$ La estabilidad de los Gobiernos españoles ha sido proverbial pues desde la entrada en vigor de la Constitución de 1978 se han sucedido nueve legislaturas de las Cortes Generales, habiendo elegido el Congreso de los Diputados sólo a cinco personas como presidentes del Gobierno de la Nación: Adolfo Suárez y Leopoldo Calvo-Sotelo en la I Legislatura (1979-1982); Felipe González en las Legislaturas II (1982-1986), III (1986-1989), IV (1989-1993) y V (1993-1996); José María Aznar en las Legislaturas VI (1996-2000) y VII (2000-2004); y José Luis Rodríguez Zapatero en las Legislaturas VIII (2004-2008) y IX (iniciada en 2008).

${ }^{8}$ Propuesta de reforma de Estatuto político de la Comunidad de Euskadi presentada por el Parlamento Vasco (Boletín Oficial de las Cortes Generales, VIII Legislatura, Serie B: Proposiciones de Ley, 21 de enero de 2005, $\left.n^{\circ} 149-1\right)$.

${ }^{9}$ En realidad también se tramitaron otros dos: la Propuesta de reforma del Estatuto de Autonomía de Canarias, presentada el 14 de septiembre de 2006 en el Congreso de los Diputados, que fue retirada en enero de 2008; y la Propuesta de reforma del Estatuto de Autonomía de Castilla-La Mancha presentada el 1 de febrero de 2007 y que ha continuado tramitándose en la actual Legislatura.

${ }^{10}$ Ley orgánica 1/2006, de 10 de abril, de Reforma de la Ley Orgánica 5/1982, de 1 de julio, de Estatuto de Autonomía de la Comunidad Valenciana (BOE n ${ }^{\circ}$ 86, de 11 de abril de 2006). 
de julio de 2006) $)^{11}$, el balear (28 de febrero de 2007) ${ }^{12}$, el andaluz (19 de marzo de 2007) ${ }^{13}$, el aragonés (20 de abril de 2007) ${ }^{14}$ y el castellano-leonés (30 de noviembre de 2007 ${ }^{15}$. Ya en la actual legislatura las Cortes Generales asimismo, se acaba de adoptar la reforma del Estatuto de Navarra (27 de octubre de $2010)^{15 b i s}$ y se tramitan los proyectos de reforma de los Estatutos castellano- manchego $^{16}$ y extremeño ${ }^{17}$.

Es difícil hacer una clasificación de los seis Estatutos de autonomía aprobados hasta ahora pero indudablemente en sus respectivas elaboraciones el enfoque ha sido muy distinto en el caso del Estatuto catalán respecto de los demás. En la elaboración del vigente Estatuto catalán las fuerzas políticas regionales que lo propusieron apostaron por un Estatuto de máximos y apuraron hasta extremos que sólo mediante negociaciones y transacciones finales se suavizaron por el Gobierno socialista de la Nación y con la reticencia del Partido conservador de la oposición. En cambio, en los otros cinco hubo consenso entre los dos partidos estatales mayoritarios; aun cuando en unos casos se pretendió imitar, ciertamente de modo muy matizado, el maximalismo catalán, como la opción en el caso del Estatuto andaluz, en los demás se prefirió un perfil más técnico y mucho menos politizado.

${ }^{11}$ Ley orgánica 6/2006, de 19 de julio, de reforma del Estatuto de Autonomía de Cataluña $\left(B O E \mathrm{n}^{\circ} 172\right.$, de 20 de julio de 2006).

${ }^{12}$ Ley Orgánica 1/2007, de 28 de febrero, de reforma del Estatuto de Autonomía de las Illes Balears $\left(B O E \mathrm{n}^{\circ}\right.$ 52, de 1 de marzo de 2007).

13 Ley Orgánica 2/2007, de 19 de marzo, de reforma del Estatuto de Autonomía para Andalucía $\left(B O E \mathrm{n}^{\circ} 68\right.$, de 20 de marzo de 2007).

${ }^{14}$ Ley Orgánica 5/2007, de 20 de abril, de reforma del Estatuto de Autonomía de Aragón $\left(B O E \mathrm{n}^{\circ}\right.$ 97, de 23 de abril de 2007).

${ }^{15}$ Ley Orgánica 14/2007, de 30 de noviembre, de reforma del Estatuto de Autonomía de Castilla y León $\left(B O E \mathrm{n}^{\circ}\right.$ 288, de 1 de diciembre de 2007).

${ }^{15 b i s}$ Ley Orgánica 7/2010, de 27 de octubre, de reforma de la Ley Orgánica 13/1982, de 10 de agosto, de reintegración y amejoramiento del Régimen Foral de Navarra (BOE n⿳0 261, de 28 de octubre de 2010).

${ }^{16}$ Congreso de los Diputados, Propuesta de reforma del Estatuto de Autonomía de Castilla-La Mancha, presentado el 1 de abril de 2008 y que, no obstante, parece haber encallado su tramitación en abril de 2010.

17 Congreso de los Diputados, Propuesta de reforma del Estatuto de Autonomía de la Comunidad Autónoma de Extremadura, presentado el 28 de septiembre de 2009. 
Esta distinción entre el Estatuto catalán y los demás se observa, aunque de manera tenue, en las cláusulas europeas: muy minuciosas y detalladas en el Estatuto catalán y, por imitación, en el Estatuto andaluz; y, por lo general, mucho más genéricas en los demás Estatutos valenciano, balear, aragonés, castellano-leonés y navarro.

Así pues, en todos los Estatutos renovados se recoge un apartado especial, con un contenido mínimo muy similar, dedicado a la participación de las Comunidades Autónomas en la Unión Europea que utiliza títulos bien distintos: en el caso del Estatuto catalán el capítulo dedicado a estas cuestiones se titula: 'Relaciones de la Generalitat con la Unión Europea'; los Estatutos valenciano, balear y aragonés se refieren en un apartado específico a las 'Relaciones con la Unión Europea'; el Estatuto castellano-leonés aporta una interesante precisión titulando el capítulo correspondiente en estos términos: 'Relaciones con la Unión Europea y participación en la política europea del Estado'.

Todas las reformas y las renovaciones de los Estatutos de autonomía contienen un elenco de cláusulas europeas que, básicamente, pueden clasificarse en torno a estos aspectos. En primer lugar pretenden poner de manifiesto la identidad de cada Comunidad Autónoma en Europa y subrayan la existencia de relaciones entre la respectiva Comunidad Autónoma y la Unión Europea, diferenciadas, por una parte, de las propias relaciones entre niveles de gobierno dentro de España, y, a la vez, especializadas en el ámbito de las 'relaciones exteriores'. En segundo lugar, los nuevos Estatutos realizan invocaciones a la dimensión europea en relación con los nuevos derechos fundamentales 'estatutarios'. Y, en tercer lugar, se regula la participación en la formación de la voluntad de las instituciones y órganos de la Unión Europea y se procura la implicación de cada Comunidad Autónoma en la aplicación del Derecho y de las políticas de la Unión, incluida la gestión de los fondos europeos ${ }^{18}$.

\section{La identidad y el compromiso de las Comunidades Autó- nomas españolas en clave europea}

Las Comunidades Autónomas han aprovechado las reformas estatutarias para confesar su vocación europea y para reafirmar su compromiso con la integración europea. Existe una necesidad de anclar los nuevos Estatutos autonó-

${ }^{18}$ David ORDÓÑEZ SOLÍS, "Las relaciones entre la Unión Europea y las Comunidades Autónomas en los nuevos estatutos", Revista d'Estudis Autonòmics i Federals, n 4, 2007, pp. 69-128. 
micos en la Unión Europea bien para difuminar el que podría considerarse estrecho y a veces incómodo contexto estatal bien para encarecer la participación regional.

En el caso del Proyecto de Estatuto vasco se proclamaba en el preámbulo: «El pueblo vasco o Euskal Herria es un pueblo con identidad propia en el conjunto de los pueblos de Europa». Más atenuadamente y con la idea de reafirmación europea, es significativo que el preámbulo del nuevo Estatuto catalán proclame: «Cataluña, a través del Estado, participa en la construcción del proyecto político de la Unión Europea, cuyos valores y objetivos comparte». Y el artículo 3.2 del mismo Estatuto catalán reconoce: «Cataluña tiene en el Estado español y en la Unión Europea su espacio político y geográfico de referencia e incorpora los valores, los principios y las obligaciones que derivan del hecho de formar parte de los mismos».

En el Estatuto andaluz en su artículo 1.4 se prevé: «La Unión Europea es ámbito de referencia de la Comunidad Autónoma, que asume sus valores y vela por el cumplimiento de sus objetivos y por el respeto de los derechos de los ciudadanos europeos». En un sentido muy similar, el artículo 1.2 del reformado Estatuto castellano-leonés proclama: «La Comunidad de Castilla y León, como región de Europa, asume los valores de la Unión Europea y vela por el cumplimiento de sus objetivos y por la defensa de los derechos reconocidos en el ordenamiento jurídico europeo».

Esto es lo que proclama también el preámbulo del Estatuto aragonés conforme al cual y por una parte: «Este Estatuto [aragonés] se abre a nuevos horizontes como el de su vocación europea, asociada a su tradicional voluntad de superar fronteras...». Y, por otra parte, de manera más precisa: «El presente Estatuto sitúa a Aragón en el lugar que, como nacionalidad histórica, le corresponde dentro de España y, a través de ella, su pertenencia a la Unión Europea...».

También el preámbulo de la reforma del Estatuto balear señala: «las Illes Balears, mediante su Estatuto, pretenden continuar en su proceso colectivo de avanzar hacia su autogobierno en el marco del Estado Español y la Unión Europea».

Estas proclamaciones tienen un valor retórico y enfático indudable, pero no dejan de adelantarse a la Constitución española que, hasta ahora, no cuenta con una cláusula europea específica a pesar de los proyectos convenientemente con- 
sensuados al efecto ${ }^{19}$. En cambio, en otros casos, como ocurría con el proyecto de nuevo Estatuto canario al proclamar las Islas Canarias como «región ultraperiférica de la Unión Europea» se estaba aplicando las mismas previsiones constitucionales de la Unión Europea.

$\mathrm{Al}$ mismo tiempo y ya con un propósito práctico patente, los nuevos Estatutos dedican algunas de sus cláusulas a fomentar la cooperación con las regiones de la Unión Europea.

Así, por ejemplo, el Estatuto valenciano en su artículo 61.3.e) atribuye a la Comunitat valenciana la facultad de «participar, de forma especial, en el marco de la Asociación Euromediterránea»; y también en su artículo 61.4 dispone: «La Generalitat, igualmente, podrá formar parte y participar en organizaciones e instituciones supranacionales de carácter regional».

El Estatuto catalán recoge en su artículo 197 una regulación de la 'Cooperación transfronteriza, interregional y al desarrollo' y, por lo que ahora interesa, dispone en su apartado 1: «La Generalitat debe promover la cooperación con las regiones europeas con las que comparte intereses económicos, sociales, ambientales y culturales, y debe establecer las relaciones que correspondan».

Y la cooperación transfronteriza con otras regiones europeas viene recogida, por ejemplo en el Estatuto aragonés, en el ámbito de las relaciones internacionales. Así, el artículo 98.1 dispone: «La Comunidad Autónoma de Aragón, como territorio limítrofe, promoverá la cooperación con las regiones europeas con las que comparte, por dicho carácter, intereses económicos, sociales, ambientales y culturales».

\section{Los nuevos derechos fundamentales estatutarios en el contexto europeo}

Los nuevos Estatutos de autonomía consagran unos 'derechos estatutarios' de carácter fundamental. Aun cuando ha limitado el alcance de esta estatutarización, en la medida en que «los Estatutos de Autonomía no pueden establecer

${ }^{19}$ Véase, por todos, el Informe E-1/2006, de 16 de febrero de 2006, sobre modificaciones de la Constitución española del Consejo de Estado (Pleno); también la publicación El Informe del Consejo de Estado sobre la reforma constitucional. Texto del informe y debates académicos, Consejo de Estado y Centro de Estudios Políticos y Constitucionales, Madrid, 2006. 
por sí mismos derechos subjetivos en sentido estricto, sino directrices, objetivos o mandatos a los poderes públicos autonómicos», no hay duda de que el Tribunal Constitucional ha tolerado su regulación y les ha reconocido efectos interpretativos $^{20}$.

La consagración de nuevos derechos fundamentales estatutarios es propia y peculiar del Estatuto catalán y, aunque más discretamente desde el punto de vista político, se ha reproducido en los otros cinco estatutos. A tal efecto y casi de modo sistemático, todos los Estatutos contienen directa o indirectamente referencias al Convenio Europeo de Derechos Humanos y en algunos supuestos a la Carta de los Derechos Fundamentales de la Unión.

Así, el reformado artículo 8 del Estatuto valenciano señala: «Los valencianos y valencianas, en su condición de ciudadanos españoles y europeos, son titulares de los derechos, deberes y libertades reconocidos en la Constitución Española y en el ordenamiento de la Unión Europea y en los instrumentos internacionales de protección de los derechos humanos, individuales y colectivos, en particular, en la Declaración Universal de Derechos Humanos; en los Pactos Internacionales de Derechos Civiles y Políticos y de Derechos Económicos, Sociales y Culturales; en la Convención Europea de Derechos del Hombre y Libertades Fundamentales, y en la Carta Social Europea».

Con más intensidad, el Estatuto catalán proclama una serie de derechos fundamentales estatutarios y en todo caso enmarca su actuación en la Unión Europea, tal como resulta del artículo 4.1 del nuevo Estatuto que prevé: «Los poderes públicos de Cataluña deben promover el pleno ejercicio de las libertades y los derechos que reconocen el presente Estatuto, la Constitución, la Unión Europea, la Declaración Universal de Derechos Humanos, el Convenio Europeo para la Protección de los Derechos Humanos y los demás tratados y convenios internacionales suscritos por España que reconocen y garantizan los derechos y las libertades fundamentales».

20 TC (Pleno) sentencia n ${ }^{\circ}$ 247/2007, de 12 de diciembre (reforma del Estatuto valenciano) (ponente: Pérez Vera, FJ 15); que termina en estos términos: «si el legislador estatutario va más allá de la mera reproducción e incide en los derechos fundamentales, tales previsiones, que tendrán la eficacia señalada en el párrafo c) anterior, sólo serán legítimas si, además, guardan relación con alguna de las competencias asumidas por la Comunidad Autónoma, incurriendo en inconstitucionalidad en caso contrario». Y en el mismo sentido la sentencia $n^{\circ} 31 / 2010$, de 28 de junio (FJ 16). 
El Estatuto balear proclama en su nuevo artículo 12.2: «Este Estatuto reafirma, en el marco de las competencias de la Comunidad Autónoma, los derechos fundamentales que emanan de la Constitución, de la Carta de los Derechos Fundamentales de la Unión Europea, del Convenio Europeo para la protección de los Derechos Humanos y de las Libertades Fundamentales y de los tratados y los acuerdos sobre la materia ratificados por el Estado». En cambio, el Estatuto andaluz no cita expresamente la Carta comunitaria aunque sí, en su artículo 9, el Convenio Europeo para la Protección de los Derechos Humanos y de las Libertades Fundamentales y la Carta Social Europea.

No obstante, el nuevo Estatuto aragonés consagra derechos y principios fundamentales sin hacer referencia explícita al Convenio Europeo ni a la Carta de la Unión y el artículo 6.1 hace una remisión genérica a «los derechos y libertades de los aragoneses y aragonesas [que] son los reconocidos en la Constitución, los incluidos en la Declaración Universal de Derechos Humanos y en los demás instrumentos internacionales de protección de los mismos suscritos o ratificados por España».

De modo muy similar el artículo 8 del Estatuto castellano-leonés dispone: «Los ciudadanos de Castilla y León tienen los derechos y deberes establecidos en la Constitución Española, en los Tratados Internacionales sobre Derechos Humanos ratificados por España, en el ordenamiento de la Unión Europea, así como los establecidos en el ámbito de la Comunidad Autónoma por el presente Estatuto de Autonomía».

En suma, los nuevos Estatutos de autonomía utilizan, directa o indirectamente, una referencia al Derecho europeo de los derechos humanos como un modo de significarse y de distinguir la norma fundamental de la Comunidad Autónoma respectiva.

\section{Las cláusulas de participación de las Comunidades Autó- nomas en las instituciones de la Unión Europea}

Ya de manera específica y por lo que se refiere a la participación institucional de las Comunidades Autónomas en la Unión Europea, los nuevos Estatutos han tenido en cuenta a las distintas instituciones -Parlamento Europeo, Consejo, Comisión y Tribunal de Justicia y órganos -Comité de las Regiones de la Unión Europea y han establecido una Delegación ante la Unión Europea.

El artículo 61 del Estatuto valenciano se dedica casi en su totalidad a previsiones de participación institucional de la Comunidad Valenciana: mediante 
una Delegación en Bruselas, en el Comité de las Regiones e incluso prevé la creación de un «Comité Valenciano para los Asuntos Europeos, órgano de carácter consultivo, encargado de asesorar y realizar estudios y propuestas para mejorar la participación en las cuestiones europeas y plantear acciones estratégicas de la Comunitat Valenciana».

El Estatuto catalán contiene unas previsiones mejor estructuradas y, desde luego, más ambiciosas. A tal efecto, regula con cierto detalle la implicación de Cataluña en el proceso de modificación de los Tratados constitutivos de la Unión, en la formación de la posiciones del Estado y en la participación en instituciones y organismos europeos (citando expresamente el Consejo, la Comisión y el Parlamento Europeo, pero no el Comité de las Regiones); desde el punto de vista institucional, el Estatuto catalán reclama la aplicación del principio de subsidiariedad y de proporcionalidad, y se preocupa de las acciones ante el Tribunal de Justicia.

En la sentencia $\mathrm{n}^{\circ} 31 / 2010$, de 28 de junio, el Tribunal Constitucional reclama una interpretación que tenga en cuenta, en particular, el contexto normativo estatal. En efecto, a juicio del Tribunal Constitucional: «... la participación de la Generalitat en los asuntos relacionados con la Unión Europea que afecten a las competencias o intereses de Cataluña tendrá lugar 'en los términos que establecen el presente Estatuto y la legislación del Estado'. Ello supone que, al margen de las genéricas previsiones del Estatuto sobre dicha participación contenidas en los preceptos que forman parte de aquel Capítulo, a algunas de las cuales nos referiremos con ocasión de su impugnación, es a la legislación del Estado a la que corresponde libremente determinar los concretos supuestos, términos, formas y condiciones de esa participación (conforme a lo ya señalado en los fundamentos jurídicos 111 y 115)» (FJ 118).

Del mismo modo y sobre la participación de Cataluña en la celebración de los Tratados constitutivos de la Unión Europea, el Tribunal Constitucional se pronuncia en su sentencia $n^{\circ} 31 / 2010$, de 28 de junio, considerando que el artículo 185.1 del nuevo Estatuto catalán es una manifestación «del principio de cooperación entre el Estado y la Comunidad Autónoma en asuntos, como los europeos, en que resultan especialmente afectados las competencias y los intereses autonómicos». Y a continuación, el Tribunal Constitucional recuerda: «aunque el ius contrahendi es una competencia exclusiva del Estado en virtud del art. 149.1.3 CE, nuestra Constitución no impide que la cooperación entre el Estado y las Comunidades Autónomas se proyecte en relación con los tratados internacionales, condición de la que participan los tratados de la Unión Europea. Así, hemos admitido que las Comunidades Autónomas puedan ejercer ciertas facul- 
tades limitadas respecto al proceso de elaboración de los tratados (capacidad de instar su celebración, recepción de información, entre otras) siempre que no pongan en cuestión las competencias del Estado para su celebración y formalización (STC 137/1989, de 20 de julio, FJ 4). El precepto ahora examinado responde, como ya se ha dicho más atrás, al mismo criterio, ya que los derechos a la información y a presentar observaciones que en él se recogen están desprovistos de efectos lesivos para la competencia estatal derivada del art. 149.1.3 CE (STC 165/1994, de 26 de mayo, FJ 8) y, de acuerdo con la previsión del art. 184 EAC, la participación de la Generalitat se vincula a que se encuentren implicados las competencias o los intereses de Cataluña. Ni el contenido del precepto penetra en la reserva estatal del art. 149.1.3 CE, pues, exclusivamente al Estado compete la revisión, suscripción y ratificación de los tratados de la Unión Europea, ni cabe vislumbrar vulneración alguna del art. $93 \mathrm{CE}$, fundamento último de nuestra incorporación al proceso de integración europea y de nuestra vinculación al Derecho comunitario, al que in extenso nos hemos referido en la Declaración 1/2004, de 13 de diciembre» (FJ 119).

El Estatuto andaluz sigue la estela catalana y resulta muy exhaustivo y, en algunos casos, original al contener cláusulas generales de participación institucional o de información de los órganos estatales que participan en las instituciones europeas.

Los otros Estatutos, balear, aragonés y castellano-leonés, son muy similares y mantienen un perfil netamente técnico previendo reiteradamente la mediación estatal en estos asuntos.

A título de ejemplo, el Estatuto aragonés en su artículo 92.1 establece: «La Comunidad Autónoma de Aragón participará, en los términos que establece la legislación estatal, en los asuntos relacionados con la Unión Europea que afecten a las competencias o intereses de Aragón». En cambio, el Estatuto balear contiene un artículo 108 conforme al cual: «La Comunidad Autónoma debe ser informada sobre las negociaciones relativas a los tratados originarios y fundacionales, sus revisiones y modificaciones, y también podrá participar en ellos, en su caso, formando parte de la delegación española, de acuerdo con los mecanismos multilaterales internos que se establezcan a este efecto entre el Estado y las comunidades autónomas».

Propongo, a continuación, llevar a cabo un examen en función de las instituciones europeas afectadas con el fin de comprobar el alcance y los matices que introduce cada uno de los Estatutos de autonomía en torno al Consejo donde incluyo la creación de una Delegación autonómica en Bruselas, a la Comisión Eu- 
ropea, al Parlamento Europeo, al Comité de las Regiones y, finalmente, al Tribunal de Justicia de la Unión Europea.

A. Las Comunidades Autónomas españolas y el Consejo de la Unión Europea: participación interna, representación en el Consejo y las Delegaciones autonómicas ante la Unión Europea

El Consejo sigue siendo la institución europea donde reside la clave de la toma de decisiones en la medida en que en la misma participan los representantes de los Estados. Precisamente, por exigencias de los países federales, en concreto Bélgica, ya desde el Tratado de Maastricht la redacción del vigente artículo 16.2 del Tratado de Funcionamiento de la Unión Europea dispone: «El Consejo estará compuesto por un representante de cada Estado miembro, de rango ministerial, facultado para comprometer al Gobierno del Estado miembro al que represente y para ejercer el derecho de voto».

Ahora bien, los problemas básicos que se plantean para la participación autonómica en el Consejo se han estructurado tradicionalmente en torno a tres cuestiones: la formación interna de la posición española, la participación de representantes autonómicos en los distintos niveles del Consejo y la representación ante la Unión Europea, las denominadas 'Oficinas autonómicas en Bruselas'.

Las cláusulas estatutarias suelen presentar, por una parte, una previsión de participación general en las decisiones en la Unión Europea y, por otra parte, se refieren expresamente a la participación en el Consejo de la Unión Europea.

El Estatuto valenciano hace referencia sólo indirecta al Consejo al referirse a la adopción de la posición española. De este modo la Comunitat Valenciana: «Tiene derecho a participar en todos los procesos que establezca el Estado para configurar la posición española en el marco de las instituciones europeas, cuando estén referidas a competencias propias de la Comunitat Valenciana. También a ser oída en aquellos otros que, incluso sin ser de su competencia, le afecten directa o indirectamente».

En cambio, el Estatuto catalán es mucho más explícito y detallado tanto en la participación en el Consejo como en la formación de la posición española. A tal efecto prevé en su artículo 186.1: «La Generalitat participa en la formación de las posiciones del Estado ante la Unión Europea, especialmente ante el Consejo de Ministros, en los asuntos relativos a las competencias o a los intereses de Cataluña, en los términos que establecen el presente Estatuto y la legislación sobre esta materia». Y también en el artículo 186.2 el Estatuto prevé: «La Gene- 
ralitat debe participar de forma bilateral en la formación de las posiciones del Estado en los asuntos europeos que le afectan exclusivamente».

Sobre este particular, la sentencia $n^{\circ} 31 / 2010$, de 28 de junio, puntualiza que la previsión del artículo 186.1 del Estatuto catalán «obviamente no supone ni puede significar que se atribuya la Comunidad Autónoma una participación unilateral en la formación de dichas posiciones, excluyente de la participación de otras Comunidades Autónomas en asuntos relacionados con las competencias o intereses de éstas. Más aún, hemos dicho que cuando el Estado asuma compromisos con la Unión Europea debe contar con el máximo consenso posible de las Comunidades Autónomas (STC 128/1999, de 1 de julio, FJ 10). En fin, la participación a la que se refiere el art. 186.1 EAC ha de tener lugar en los términos que se establecen en el propio Estatuto de Autonomía y en la legislación sobre la materia, que no puede ser otra que la que el Estado establezca al amparo de las diferentes competencias que le atribuye el art. 149.1 CE y que se corresponden con las diferentes políticas comunitarias, al tratarse, precisamente, del proceso de formación de las posiciones del Estado ante la Unión Europea» (FJ 120).

Y en cuanto se refiere a la participación bilateral, el Tribunal Constitucional insiste en la misma sentencia $31 / 2010$ con calculada ambigüedad: «En principio, no puede formularse ninguna objeción constitucional a que en el Estatuto de Autonomía, en tanto que norma institucional básica de la Comunidad Autónoma, se recoja, con la generalidad y abstracción con que lo hace el art. 186.2 EAC, una proclamación tan genérica sobre la forma de participación de ésta en el proceso de formación de las posiciones del Estado ante la Unión Europea en los asuntos que le afecten, atendiendo a los criterios de exclusividad o no de esa afección, dada la relevancia de las actuaciones de las instituciones europeas en el ejercicio de las competencias de las Comunidades Autónomas y el interés de éstas en dichas actuaciones, siendo evidentemente al legislador estatal a quien compete concretar los supuestos, términos, formas y condiciones de esa participación (fundamentos jurídicos 111 y 115)» (FJ 120).

Por último y en relación con la previsión del artículo 187 del Estatuto catalán que procura una implicación 'catalana' en las delegaciones españolas ante el Consejo y en la Representación de España ante la Unión Europea, la sentencia n $31 / 2010$, de 28 de junio, advierte: «No existe obstáculo, en principio, para que en el Estatuto de Autonomía, en cuanto norma institucional básica de la Comunidad Autónoma, se recojan unas previsiones como las ahora impugnadas en las que se habilita con carácter general o, como las califican los propios recurrentes, en las que se hace una referencia genérica a la participación de la Co- 
munidad Autónoma dentro de las delegaciones estatales en las instituciones y organismos europeos que se mencionan o a la participación en el proceso de designación de representantes en el marco de la representación permanente del Estado ante la Unión Europea, dado el interés de las Comunidades Autónomas en la actividad que lleven a cabo aquellas instituciones y organismos. Ahora bien, como resulta del tenor del art. 184 EAC, en su condición, a la que ya nos hemos referido, de disposición general del capítulo II del título V, que debe tenerse presente en todos los artículos que integran el referido capítulo, entre ellos el art. 187 EAC que ahora nos ocupa, y como también se desprende de las locuciones "de acuerdo con la normativa aplicable" y "de acuerdo con el Estado" de los apartados 2 y 3 del art. 187 EAG, es al Estado al que, en el ejercicio de la competencia reservada ex art. 149.1.3 CE, le corresponde determinar los concretos supuestos, términos, formas y condiciones de las participaciones indicadas en el precepto estatutario, participaciones que, además, no pueden privar al Estado de sus exclusivas facultades de decisión en este ámbito. Preservadas, pues, en todo caso estas facultades decisorias del Estado, se desvanecen, por sí, los reparos que ven en las previsiones del art. 187 EAC un impedimento a la ordenada concurrencia con otras Comunidades Autónomas cuyos Estatutos de Autonomía pudieran resultar de igual, similar o diverso contenido en esta materia. Por lo demás, en relación con la participación de la Generalitat prevista en el art. 187.1 y 2 EAC, el precepto en modo alguno otorga al representante de la Generalitat un status diplomático, ni, teniendo lugar aquella participación siempre en el seno de las delegaciones españolas, cabe apreciar una vulneración del art. 149.1.3 CE porque la Generalitat pueda ejercer, como se contempla en el art. 187.2 EAG, y, de acuerdo en todo caso con la normativa estatal, la representación y la presidencia españolas de los órganos europeos, a los que el precepto se refiere, esto es, por remisión al art. 187.1 EAC, los órganos consultivos y preparatorios del Consejo y de la Comisión» (FJ 121).

También el Estatuto andaluz sigue la estrategia catalana y de manera muy prolija regula la representación y formación de la voluntad en el artículo 234.1: «La Junta de Andalucía participa en las delegaciones españolas ante las instituciones de la Unión Europea en defensa y promoción de sus intereses y para favorecer la necesaria integración de las políticas autonómicas con las estatales y las europeas. Especialmente, participa ante el Consejo de Ministros y en los procesos de consulta y preparación del Consejo...».

Los otros tres nuevos Estatutos contienen cláusulas más generales y más modestas. Así, el Estatuto balear en su artículo 111 establece: «La Comunidad Autónoma participará en la delegación española en el Consejo de Ministros de la Unión Europea y en sus grupos de trabajo en los términos establecidos en el 
sistema general de la participación autonómica. Esta participación puede acordarse de manera directa con los órganos competentes de la Administración General del Estado en el caso que se vean afectadas especificidades propias de la Comunidad Autónoma de las Illes Balears».

En el primer apartado del artículo 93.1 del Estatuto aragonés sobre la Participación en la formación y aplicación del Derecho de la Unión se dispone: «La Comunidad Autónoma de Aragón participa en la formación de las posiciones del Estado ante la Unión Europea, especialmente ante el Consejo de Ministros, en los asuntos que incidan en las competencias o intereses de Aragón, en los términos que establecen el presente Estatuto y la legislación estatal sobre la materia». Y el artículo 94 del Estatuto aragonés se refiere a la participación en instituciones y organismos europeos en estos términos: «Los representantes de la Comunidad Autónoma de Aragón participarán de manera directa o mediante procedimientos multilaterales en las delegaciones españolas ante las instituciones y organismos de la Unión Europea que traten asuntos de su competencia, singularmente ante el Consejo de Ministros y en los procesos de consulta y preparación del Consejo y de la Comisión, de acuerdo con la legislación estatal».

En fin, el artículo 63.1 del Estatuto castellano-leonés dispone: «La Comunidad podrá participar en las instituciones y órganos de la Unión, dentro de la representación del Estado español, según lo determine la legislación aplicable».

Respecto de las 'oficinas autonómicas en Bruselas', una vez despejadas las dudas por el Tribunal Constitucional en su sentencia n ${ }^{\circ}$ 165/1994, de 26 de mayo, relativa a la Oficina vasca en Bruselas, los nuevos Estatutos han elevado el rango de las Oficinas a Delegaciones aspirando, sin duda, a contar algún día con Representaciones Permanentes autonómicas ante la Unión Europea. Nótese que se intenta pasar de meras oficinas autonómicas en Bruselas a Delegaciones o Representaciones ante la Unión Europea.

Por una parte, el Tribunal Constitucional había considerado en la referida sentencia n ${ }^{\circ}$ 165/1994: «cuando España actúa en el ámbito de las Comunidades Europeas lo está haciendo en una estructura jurídica que es muy distinta de la tradicional de las relaciones internacionales. Pues el desarrollo del proceso de integración europea ha venido a crear un orden jurídico, el comunitario, que para el conjunto de los Estados componentes de las Comunidades Europeas puede considerarse a ciertos efectos como "interno". En correspondencia con lo anterior, si se trata de un Estado complejo, como es el nuestro, aun cuando sea el Estado quien participa directamente en la actividad de las Comunidades Europeas y no las CG.AA., es indudable que éstas poseen un interés en el desarrollo 
de esa dimensión comunitaria. Por lo que no puede sorprender, de un lado, que varias CG.AA. hayan creado, dentro de su organización administrativa, departamentos encargados del seguimiento y de la evolución de la actividad de las instituciones comunitarias. Y de otro lado, al igual que ocurre en el caso de otros Estados miembros de las Comunidades Europeas, que los entes territoriales, hayan procurado establecer en las sedes de las instituciones comunitarias, mediante formas organizativas de muy distinta índole, oficinas o agencias, encargadas de recabar directamente la información necesaria sobre la actividad de dichas instituciones que pueda afectar, mediatamente, a las actividades propias de tales entes» ${ }^{21}$.

El artículo 61 del reformado Estatuto valenciano prevé: «La Comunitat Valenciana tendrá una Delegación en Bruselas como órgano administrativo de representación, defensa y promoción de sus intereses multisectoriales ante las instituciones y órganos de la Unión Europea».

El nuevo Estatuto catalán establece la Delegación de la Generalitat ante la Unión Europea: «La Generalitat establecerá una delegación para la mejor defensa de sus intereses ante las instituciones de la Unión Europea».

Y también en el artículo 236 del Estatuto andaluz se señala: «La Junta de Andalucía tendrá una Delegación Permanente en la Unión Europea como órgano administrativo de representación, defensa y promoción de sus intereses ante las instituciones y órganos de la misma, así como para recabar información y establecer mecanismos de relación y coordinación con los mismos».

El artículo 107 del Estatuto balear prevé: «La Comunidad Autónoma puede establecer delegaciones u oficinas de representación ante la Unión Europea para mejorar el ejercicio de sus competencias y promover adecuadamente sus intereses».

El artículo 92 del Estatuto aragonés se expresa con el siguiente tenor: «La Comunidad Autónoma de Aragón establecerá una delegación para la presentación, defensa y promoción de sus intereses ante las instituciones y órganos de la Unión Europea».

\footnotetext{
21 TC (Pleno), sentencia n ${ }^{\circ}$ 165/1994, de 26 de mayo de 1994 (ponente: López Guerra, FJ $4)$.
} 
En fin, el Estatuto castellano-leonés dispone en su artículo 64: «La Comunidad de Castilla y León podrá establecer una Delegación Permanente ante la Unión Europea con el fin de mantener relaciones de colaboración con las instituciones europeas y de ejercer funciones de información y de promoción y defensa de los intereses de Castilla y León».

\section{B. Las Comunidades Autónomas españolas, la Comisión Europea y el Comité de las Regiones}

Las relaciones de las Comunidades Autónomas con la Comisión Europea y con el Comité de las Regiones son de gran importancia pero, al menos, en cuanto se refiere a la participación autonómica en la Comisión Europea presentan más problemas por tratarse de una institución independiente. En efecto y tal como presenta se deduce del artículo 17.3 del Tratado de la Unión Europea: «La Comisión ejercerá sus responsabilidades con plena independencia [...] los miembros de la Comisión no solicitarán ni aceptarán instrucciones de ningún gobierno, institución, órgano u organismo. Se abstendrán de todo acto incompatible con sus obligaciones o con el desempeño de sus funciones».

Sin embargo, el equilibrio institucional diseñado en los Tratados comunitarios ha generado un procedimiento de comitología que constituye un mecanismo de control del Consejo sobre los poderes de ejecución de la Comisión Europea. Es precisamente por este ascendiente del Consejo sobre la Comisión Europea por lo que se puede prever una participación autonómica en la adopción de decisiones por la Comisión Europea.

Sólo algunos Estatutos aluden a estas relaciones con la Comisión Europea. Así, el artículo 234 del Estatuto andaluz menciona los procesos de consulta y preparación del Consejo y la Comisión Y también, el artículo 94 del Estatuto aragonés se refiere a la participación en instituciones y organismos europeos, citando expresamente los procesos de consulta y preparación de la Comisión, de acuerdo con la legislación estatal, lo que puede interpretarse como una referencia al procedimiento de comitología.

En cambio, tratándose del Comité de las Regiones parece lógico que por su denominación estuviesen integradas en este órgano consultivo las regiones europeas; sin embargo, la composición general del Comité de las Regiones atiende, de manera especial y preponderante, a las autoridades locales. Ahora bien, desde la puesta en funcionamiento en 1994 del Comité de las Regiones, los 21 escaños asignados a España son ocupados por representantes autonómicos. Así lo había acordado el 1993 el Senado español: 17 de los representantes españo- 
les provendrán de las Comunidades Autónomas (sus respectivos Presidentes, que deben tener suplentes) y los cuatro representantes restantes, y sus suplentes, proceden de los Entes locales y son propuestos por la Federación Española de Municipios y Provincias ${ }^{22}$.

En algunos de los Estatutos se menciona expresamente el derecho de participación autonómica en el Comité de las Regiones. Así, el artículo 61.3.c) del Estatuto valenciano dispone: «[La Comunitat Valenciana] tendrá al President de la Generalitat como representante de la Comunitat Valenciana en el Comité de las Regiones». Y también el artículo 63.2 del Estatuto castellano-leonés determina: «La Junta de Castilla y León propondrá al Estado la designación de representantes en el Comité de las Regiones, de conformidad con las normas que lo regulan».

C. Los Parlamentos autonómicos españoles y el Parlamento Europeo

La actividad normativa y de control de los parlamentos nacionales es imprescindible para asegurar el cumplimiento y la ejecución del Derecho de la Unión Europea pero hasta ahora y con la excepción de algunos países como Dinamarca o el Reino Unido la participación de los Parlamentos nacionales en el proceso de adopción de decisiones en la Unión Europea ha sido más bien testimonial. En este sentido, los Parlamentos nacionales han terminado comprendiendo, tras cinco décadas de integración europea, que su intervención tiene efectos legitimadores del proceso de integración europea.

Por esa razón, los más recientes cambios constitucionales persiguen, en particular, conferir un mayor protagonismo a los Parlamentos nacionales. Así lo atestigua el Protocolo $\mathrm{n}^{\circ} 1$ sobre el cometido de los Parlamentos nacionales en la Unión Europea y el Protocolo $\mathrm{n}^{\mathrm{o}} 2$ sobre la aplicación de los principios de subsidiariedad y proporcionalidad, que están anejos al Tratado de Lisboa.

Los Estatutos de Autonomía que se adoptaron al mismo tiempo que se negociaba el futuro Tratado de Lisboa han subrayado la importancia de la participación de los Parlamentos regionales en la integración europea bien con una mención directa bien con una referencia a la aplicación del principio de subsidiariedad.

\footnotetext{
${ }^{22}$ Moción del Senado, de 20 de octubre de 1993, relativa a la composición de la delegación española en el Comité de las Regiones (Boletín Oficial de las Cortes Generales n 34, Senado, V Legislatura, Serie I, 28 de octubre de 1993, p. 11).
} 
El artículo 112 del Estatuto balear prevé: «El Parlamento de las Illes Balears puede ser consultado por las Cortes Generales en el marco del proceso de control del principio de subsidiariedad establecido en el Derecho Comunitario».

El artículo 93.3 del Estatuto aragonés prevé: «Las Cortes de Aragón participarán en los procedimientos de control de los principios de subsidiariedad y proporcionalidad que establezca la Unión Europea en relación con las propuestas legislativas europeas cuando afecten a competencias de la Comunidad Autónoma».

De hecho, la entrada en vigor del Tratado de Lisboa ha acelerado en España la reorganización institucional y la actividad legislativa en el marco precisamente de la presidencia española del Consejo durante primer semestre de 2010. El ejemplo más paradigmático lo constituye la reorganización mediante la Ley 24/2009, de 22 de diciembre, relativa a la Comisión Mixta adaptación del Congreso y del Senado para la Unión Europea ${ }^{23}$. Sobre de la Comisión Mixta este particular, el preámbulo de la Ley explica que su razón de ser deriva de «la posibilidad prevista en el Protocolo anejo al Tratado de Lisboa consistente en que los parlamentos nacionales puedan consultar a los parlamentos regionales que posean competencias legislativas». Los nuevos procedimientos de participación de las Cortes Generales previstos en la Unión Europea se adaptan a la implicación de los Parlamentos autonómicos: «Esta posibilidad se articula de forma general, mediante la remisión a los parlamentos de las Comunidades Autónomas de todas las iniciativas legislativas europeas, tan pronto se reciban, sin prejuzgar la existencia de competencias autonómicas afectadas. Dichos parlamentos disponen de un plazo de cuatro semanas para que su dictamen pueda ser tenido en cuenta por la Comisión Mixta, la cual, si aprobase un dictamen motivado sobre la vulneración del principio de subsidiariedad por un proyecto de acto legislativo de la Unión Europea, deberá incorporar la relación de los dictámenes remitidos por los parlamentos de las Comunidades Autónomas y las referencias necesarias para su consulta».

${ }^{23}$ Ley 24/2009, de 22 de diciembre, de modificación de la Ley 8/1994, de 19 de mayo, por la que se regula la Comisión Mixta para la Unión Europea, para su adaptación al Tratado de Lisboa de 13 de diciembre de 2007 (BOE n ${ }^{\circ}$ 308, de 23 de diciembre de 2009). El artículo 6.1 de esta Ley dispone: «El Congreso de los Diputados y el Senado, tan pronto reciban una iniciativa legislativa de la Unión Europea, la remitirán a los Parlamentos de las Comunidades Autónomas, sin prejuzgar la existencia de competencias autonómicas afectadas, a efectos de su conocimiento y de que, en su caso, puedan remitir a las Cortes Generales un dictamen motivado sobre la aplicación del principio de subsidiariedad por la referida iniciativa, todo ello de conformidad con lo dispuesto en la normativa europea aplicable en la materia». 
Como es obvio, sólo el interés y el esfuerzo de participación de los Parlamentos autonómicos y, desde luego, de las dos Cámaras del Parlamento español, en particular del desaprovechado Senado, permitirán que fructifique la nueva regulación de la Comisión Mixta para la Unión Europea y las previsiones estatutarias sobre participación de los Parlamentos regionales.

D. Las Comunidades Autónomas españolas ante el Tribunal de Justicia de la Unión Europea

De una manera muy detallada los nuevos Estatutos de Autonomía, con la salvedad del valenciano, se refieren a la presencia autonómica ante el Tribunal de Justicia. Esta regulación resulta sorprendente porque, en términos generales, es una cuestión regulada en el Derecho de la Unión Europea y sólo tiene una mínima dimensión nacional.

El artículo 191 del Estatuto catalán se refiere a las 'Acciones ante el Tribunal de Justicia' y distingue una doble dimensión: la europea y la estatal. Y en su apartado 1 dispone: «La Generalitat tiene acceso al Tribunal de Justicia de la Unión Europea en los términos que establezca la normativa europea» lo que no deja de ser una mera referencia normativa sin sustancia alguna.

En cambio, más contenido tiene la participación autonómica ante el Tribunal de Justicia a través de la representación estatal: por una parte, el Estatuto catalán consagra el derecho de solicitar la actuación del Gobierno de la Nación en estos términos: «El Gobierno de la Generalitat puede instar al Gobierno del Estado a iniciar acciones ante el Tribunal de Justicia de la Unión Europea en defensa de los legítimos intereses y competencias de la Generalitat»; en segundo lugar, exige una motivación de la denegación de la actuación: «La negativa del Gobierno del Estado a ejercer las acciones solicitadas debe ser motivada y se comunicará inmediatamente a la Generalitat»; y, por último, reclama un preciso mecanismo de colaboración de la Generalitat «en la defensa jurídica».

Con un esquema similar pero más alambicado el artículo 238 del nuevo Estatuto andaluz se refiere a las 'Acciones ante el Tribunal de Justicia': primero, se refiere a la aplicación de la legislación estatal: «La Junta de Andalucía interviene en los procedimientos ante el Tribunal de Justicia de la Unión Europea en los términos establecidos por la legislación del Estado»; a continuación, invoca el Derecho de la Unión: «Tendrá acceso, en su caso, al mismo si así lo establece la legislación comunitaria»; y, por último, consagra el derecho de solicitud al Estado pero también a las instituciones -se entiende que europeas y en principio y con toda probabilidad se refiera a la Comisión Europea en estos términos: «En 
el marco de la legislación vigente en la materia, la Junta de Andalucía podrá instar al Estado y a las instituciones legitimadas el inicio de acciones ante el Tribunal de Justicia de la Unión Europea en defensa de los intereses de la Comunidad Autónoma». Pero también el artículo 233 del Estatuto andaluz contiene una cláusula general sobre 'Información del Estado' que, entre otras, ofrece esta perspectiva: «El Estado informará a la Junta de Andalucía [...] de los procedimientos que se sigan ante los órganos judiciales europeos en los que España sea parte, en lo que afecte al interés de Andalucía, conforme a lo establecido en la normativa estatal. La Junta de Andalucía podrá dirigir al Estado las observaciones y propuestas que estime convenientes».

El artículo 113 del reformado Estatuto balear es un poco más genérico y ofrece la doble dimensión estatal y europea, previendo que pueda instar al Estado y a las instituciones legitimadas para actuar ante el Tribunal de Justicia.

En primer lugar y por lo que se refiere al ámbito nacional dispone: «La Comunidad Autónoma interviene en los procesos ante el Tribunal de Justicia de la Unión Europea en los términos establecidos por la legislación del Estado»; a continuación, respecto del marco europeo: «Tendrá acceso en su caso al mismo si así lo establece la legislación comunitaria». Y, por último, en cuanto al derecho de solicitud al Estado o a las instituciones (se entiende que europeas) indica: «En el marco de la legislación vigente en la materia, la Comunidad Autónoma podrá, en defensa de sus intereses, instar al Estado y a las instituciones legitimadas el inicio de acciones ante el Tribunal de Justicia de la Unión Europea».

El nuevo Estatuto aragonés tiene un artículo 95 cuya redacción es muy similar a la catalana pero con un carácter más genérico. Por una parte, se remite al Derecho de la Unión: «La Comunidad Autónoma tiene acceso al Tribunal de Justicia de la Unión Europea en los términos que establezca la normativa europea». Y, por otra parte, establece una regulación dentro del marco nacional español: «El Gobierno de Aragón puede instar al Gobierno de España la interposición de acciones ante el Tribunal de Justicia de la Unión Europea en defensa de los intereses y competencias de la Comunidad Autónoma».

El mismo efecto se pretende con el artículo 65 del reformado Estatuto castellano-leonés sobre 'Acciones ante el Tribunal de Justicia de la Unión Europea'. Por una parte, recoge las dos dimensiones, europea y nacional: «La Comunidad de Castilla y León podrá actuar en los procedimientos ante el Tribunal de Justicia de la Unión Europea en los términos que establezca la legislación aplicable». Y, por otra parte, se refiere al derecho de solicitar la intervención del Estado: «En cualquier caso, la Junta de Castilla y León podrá instar al Gobierno de la Na- 
ción a ejercer acciones ante el Tribunal de Justicia de la Unión Europea en defensa de los intereses de Castilla y León».

Tampoco este tipo de cláusulas relativas al Tribunal de Justicia ha planteado problema alguno a la interpretación del Tribunal Constitucional, si acaso es significativo que en la sentencia $\mathrm{n}^{\circ} 31 / 2010$, de 28 de junio, donde la cuestión europea no suscitó debate, al menos visible entre el dividido Pleno, en el voto disidente del magistrado Rodríguez Arribas se apunta, en relación con el art. 191.1 del Estatuto catalán, este deseo: «una clarificadora interpretación conforme en el fallo, que dejara expreso en éste y no solo en los correspondientes fundamentos jurídicos de la Sentencia (FFJJ 80, 87, 124, 127 y 129) que no se menoscaba la representación española en el seno de organizaciones internacionales, ni se sitúa a una Comunidad Autónoma en paralelo con el Estado; al no hacerlo así, la Sentencia adolece de una insuficiencia potencialmente productora de situaciones de conflicto absurdo en un área, como es la internacional, especialmente sensible para el Estado y la presencia de España en actividades de gran incidencia social».

\section{Las cláusulas de participación autonómica en la ejecución del Derecho de la Unión Europea: transposición de direc- tivas y gestión de fondos europeos}

La doctrina sobre la ejecución del Derecho comunitario europeo en España fue consolidándose por el Tribunal Constitucional a partir de su primera sentencia dictada a finales de 1988, se reafirmó en 1992 y desde 1995 apenas si ha sido corregida ligeramente. La referida jurisprudencia se inicia con la sentencia $n^{\circ}$ 252/1988, de 20 de diciembre, relativa al conflicto de competencias entre Cataluña y el Estado en materia de inspección veterinaria de intercambio de carnes frescas en aplicación de directivas comunitarias ${ }^{24}$. Pero ya de modo muy claro el Tribunal Constitucional se pronunció en su sentencia 79/1992, de 28 de mayo, relativa a los conflictos de competencias en la gestión del Fondo agrícola, consagrando su doctrina conforme a la cual la ejecución del Derecho comunitario no altera la distribución constitucional de competencias entre el Estado y las Comunidades Autónomas ${ }^{25}$.

24 TC (Pleno), sentencia no 252/1988, de 20 de diciembre (ponente: Rubio Llorente).

25 TC (Pleno), sentencia 79/1992, de 28 de mayo (ponente: Rodríguez Bereijo). 
En estos términos resume el Tribunal Constitucional en su sentencia $\mathrm{n}^{\circ}$ 80/1993, de 8 de marzo, los principios básicos de la ejecución del Derecho comunitario en España: «en relación ya directa con la problemática de la ejecución del Derecho Comunitario, son las reglas internas de delimitación competencial las que, en todo caso, han de fundamentar la respuesta a los conflictos de competencia surgidos entre el Estado y las Comunidades Autónomas (STC 252/1988 y en términos reiterativos, SSTC 76/1991 y 115/1991), tal como, además, se reconoce desde el propio Derecho Comunitario, en el que consolidada jurisprudencia del Tribunal de Justicia ha consagrado el llamado principio de autonomía institucional y procedimental, en virtud del cual, cuando las disposiciones de los Tratados o demás normas comunitarias reconocen poderes a los Estados miembros o les imponen obligaciones en orden a la aplicación del Derecho Comunitario, la cuestión de saber de qué forma el ejercicio de esos poderes y la ejecución de las obligaciones pueden ser confiadas por los Estados miembros a determinados órganos internos depende únicamente del sistema constitucional de cada Estado miembro» ${ }^{26}$.

Pero también y como ocurre en la Unión Europea, donde los principios de subsidiariedad y cooperación leal tienen una plasmación constitucional y una interpretación jurídica efectiva, en el Estado de las Autonomías y, más en particular, tratándose de participar en la Unión Europea se hace imprescindible recurrir a los principios de colaboración o cooperación y de coordinación entre el Estado central y las Comunidades Autónomas.

Con carácter general, así lo señala reiteradamente el Tribunal Constitucional, como se deduce, por ejemplo de una de sus últimas e importantes sentencias, la ya citada 247/2007, de 12 de diciembre, referida precisamente a la impugnación del reformado Estatuto valenciano y donde señala: «debemos reiterar de nuevo que el adecuado funcionamiento del Estado Autonómico se sustenta en los principios de cooperación y coordinación entre el Estado y las Comunidades Autónomas y de éstas entre sí, además de en el establecimiento de un sistema de relaciones presididas por la lealtad constitucional, principios todos ellos que deben hacerse efectivos al margen, incluso, del régimen de distribución competencial».

Y ya en relación con la participación en los asuntos europeos resulta clásica la referencia a la colaboración entre el Estado y las Comunidades Autónomas

${ }^{26}$ TC (Pleno), sentencia n ${ }^{\circ}$ 80/1993, de 8 de marzo de 1993 (ponente: Gimeno Sendra, FJ $3)$. 
en la citada sentencia $\mathrm{n}^{\circ} 79 / 1992$, de 28 de mayo, relativa a la gestión administrativa de las subvenciones europeas agrarias en España, donde el Tribunal Constitucional puntualiza: «No corresponde, sin embargo, a este Tribunal, que no es juez de la oportunidad política o técnica, diseñar cuál sea la fórmula precisa preferible para la articulación de las competencias del Estado y de las Comunidades Autónomas en casos en que, como aquí se trata, están abocados a una necesaria colaboración. Sin duda las fórmulas que pueden adoptarse dentro del marco constitucional y estatutario son variadas. Pero este Tribunal sólo puede pronunciarse sobre la legitimidad de aquélla que es objeto de conflicto de competencias sin que, caso de afirmarse su validez, ello signifique que sea la única admisible dentro del orden constitucional de competencias» (FJ 4).

Las cláusulas europeas recogidas en los Estatutos de Autonomía se refieren a esta cuestión y codifican e introducen algunas innovaciones en el marco político y legislativo existente. Las reformas giran en torno a tres aspectos: por una parte, la competencia autonómica en materia de ejecución del Derecho europeo; por otra parte, una referencia expresa a la transposición de Directivas en el caso de que el Estado tenga competencias básicas y no las haya desarrollado incorporando la directiva en cuestión; y, en fin, la gestión de los fondos europeos.

a) La competencia de la ejecución del Derecho de la Unión Europea

Por lo que se refiere a la ejecución del Derecho de la Unión Europea, el artículo 61.3.d) del Estatuto valenciano reconoce que la Comunidad valenciana: «Ostenta la competencia exclusiva para el desarrollo y ejecución de las normas y disposiciones europeas en el ámbito de sus competencias».

El Estatuto catalán dispone en el artículo 189.1: «La Generalitat aplica y ejecuta el derecho de la Unión Europea en el ámbito de sus competencias. La existencia de una regulación europea no modifica la distribución interna de competencias que establecen la Constitución y el presente Estatuto».

Y a continuación consagra una obligación del Estado cuando ejecute el Derecho de la Unión que tenga incidencia en Cataluña: «Si la ejecución del derecho de la Unión Europea requiere la adopción de medidas internas de alcance superior al territorio de Cataluña que las Comunidades Autónomas competentes no pueden adoptar mediante mecanismos de colaboración o coordinación, el Estado debe consultar a la Generalitat sobre estas circunstancias antes de que se adopten dichas medidas. La Generalitat debe participar en los órganos que adopten dichas medidas o, si esta participación no es posible, debe emitir un informe previo». 
El artículo 235 del Estatuto andaluz señala: «La Junta de Andalucía desarrolla y ejecuta el derecho de la Unión Europea en las materias de su competencia, de acuerdo con lo que establezca una ley del Parlamento de Andalucía».

Este es el sentido del artículo 109 del Estatuto balear conforme al cual: «Es competencia de la Comunidad Autónoma el desarrollo y la ejecución del derecho comunitario de acuerdo con sus competencias. En el caso de que sea ineludible realizar la transposición del derecho europeo en las materias de su competencia exclusiva por normas estatales, por el hecho de que la norma europea tenga un alcance superior al de la Comunidad Autónoma, ésta será consultada con carácter previo de acuerdo con los mecanismos internos de coordinación previstos en una ley estatal».

El artículo 93.2 del Estatuto aragonés establece: «La Comunidad Autónoma de Aragón aplica y desarrolla el Derecho de la Unión Europea en el ámbito de sus competencias. La existencia de una regulación europea no modifica la distribución interna de competencias que establecen la Constitución y el presente Estatuto».

El artículo 62.3 del Estatuto castellano-leonés prevé: «La Comunidad aplica y desarrolla el Derecho de la Unión Europea en el ámbito de sus competencias. La existencia de una regulación europea no modifica la distribución interna de competencias establecida por la Constitución y el presente Estatuto».

Parece obvio que tales cláusulas son una reproducción de la doctrina del Tribunal Constitucional sin que supongan innovación jurídica alguna. Ahora bien, esta regulación estatutaria no puede entenderse si no se tiene en cuenta la legislación estatal, como en algunas ocasiones se precisa en los propios Estatutos de autonomía y, desde luego, si no se inscribe en el marco constitucional de la Unión Europea. Por decirlo, parafraseando al Tribunal Constitucional, la ejecución del Derecho europeo no se produce en el vacío sino en un contexto normativo y administrativo estatal y europeo muy determinado que, finalmente, termina afectando al reparto español de competencias. nómica

b) Las directivas europeas, la legislación básica estatal y la legislación auto-

Algunos de los Estatutos autonómicos han introducido una pequeña innovación normativa relacionada con la transposición de las directivas europeas por las Comunidades Autónomas. 
En efecto, la transposición de las directivas por las Comunidades Autónomas sin necesidad de esperar la adopción de un ley básica estatal preceptiva sería posible en Cataluña cuyo artículo 189.3 del Estatuto preceptúa: «En el caso de que la Unión Europea establezca una legislación que sustituya a la normativa básica del Estado, la Generalitat puede adoptar la legislación de desarrollo a partir de las normas europeas».

Esta es la misma cláusula del artículo 235.2 del Estatuto andaluz: «En el caso de que la Unión Europea establezca una legislación que sustituya a la normativa básica del Estado, la Junta de Andalucía podrá adoptar la legislación de desarrollo a partir de las normas europeas».

Ahora bien, los supuestos a que se refieren estas cláusulas estatutarias son limitados dado que tiene que existir una normativa básica estatal y tiene que haber una directiva europea que sustituya la norma básica estatal. Esta coincidencia no será frecuente y plantea el espinoso problema, para el caso de que la directiva incorporada deje suficiente margen de elección a las autoridades nacionales, de, si una vez incorporada la directiva al Derecho autonómico correspondiente, el Estado adopta una ley estatal básica que hace elecciones distintas de las previstas por la ley autonómica de transposición directa de la directiva europea. Parece obvio que el margen conferido por la directiva al legislador nacional no puede restringirlo el legislador autonómico hurtando la competencia correspondiente al legislador estatal básico. Ciertamente y una vez concluido el período de transposición si el Estado no cumpliese su obligación de legislador básico y hasta que lo haga, las Comunidades Autónomas podrían cubrir el vacío normativo teniendo las directivas como única referencia. Del mismo modo y en supuestos frecuentes en que las directivas dejan escaso margen al legislador nacional, este escaso margen probablemente reduzca o, en la práctica, anule la opción del legislador básico estatal y, por efecto cascada, la ya menores opciones normativas del desarrollo normativo autonómico hasta el punto de que, al menos en teoría, podía sostenerse la posibilidad de una transposición de las directivas por el legislador autonómico si el legislador básico estatal poco pudiese añadir a lo ya establecido por las directivas.

Pero también debe tenerse en cuenta lo señalado por el Tribunal Constitucional en su sentencia $\mathrm{n}^{0} 31 / 2010$, de 28 de junio, en relación con el artículo 189.3 del Estatuto catalán: «no existe razón alguna para objetar que la Comunidad Autónoma ejecute el Derecho de la Unión Europea en el ámbito de sus competencias, tal como dispone con carácter general el art. 189.1 EAC, y, en consecuencia, tampoco, en principio, para que pueda adoptar, cuando ello sea posible, legislación de desarrollo a partir de una legislación europea que sustitu- 
ya a la normativa básica del Estado en una materia. Ahora bien, una concepción constitucionalmente adecuada del precepto implica siempre la salvaguarda de la competencia básica del Estado en su caso concernida, que no resulta desplazada ni eliminada por la normativa europea, de modo que el Estado puede dictar futuras normas básicas en el ejercicio de una competencia constitucionalmente reservada, pues, como señala el Abogado del Estado, la sustitución de unas bases por el Derecho europeo no modifica constitutivamente la competencia constitucional estatal de emanación de bases» (FJ 123).

c) La gestión de los fondos europeos por las Comunidades Autónomas

A la gestión de los fondos europeos se refieren los Estatutos tanto en la regulación relativa a la Unión Europea como en las disposiciones financieras generales.

La regulación autonómica que pretendía ir más lejos era, sin duda, la del Estatuto catalán en la redacción del Parlamento de Cataluña; sin embargo, la reforma finalmente aprobada quedó en un artículo 190 sobre 'Gestión de fondos europeos' donde se prevé: «Corresponde a la Generalitat la gestión de los fondos europeos en materias de su competencia en los términos previstos en el art. 114 y $210 »$; es decir, remite a la regulación general de la gestión de subvenciones.

Esta es la cláusula del artículo 115 del Estatuto balear: «Corresponde a la Comunidad Autónoma la gestión de los fondos procedentes de la Unión Europea y, en general, de los que se canalicen a través de programas europeos, excepto aquellos cuyas competencias correspondan al Estado».

El Estatuto andaluz regula la gestión de los fondos europeos fuera del capítulo europeo y señala en el artículo 185 resumidamente las reglas aplicables: «1. Corresponde a la Comunidad Autónoma la gestión, planificación y ejecución de los fondos europeos destinados a Andalucía y, en general, de los que se canalicen a través de programas europeos, asignados a la misma, en especial de aquellos aprobados en aplicación de criterios de convergencia o derivados de la situación específica de Andalucía. 2. Los fondos que se reciban en estos conceptos podrán ser modulados con criterios sociales y territoriales por la Comunidad Autónoma de Andalucía, dentro del respeto a las normas europeas aplicables».

En el caso de Aragón, el artículo 79.2 de su nuevo Estatuto se refiere a la actividad de fomento y señala: «En el caso de las competencias exclusivas, la Comunidad Autónoma especificará los objetivos a los que se destinen las subven- 
ciones territorializables de la Administración central y las de la Unión Europea, así como la regulación de las condiciones de otorgamiento y la gestión de su tramitación y concesión. En las competencias compartidas, la Comunidad Autónoma precisará normativamente los objetivos de las subvenciones territorializables de la Administración central y de la Unión Europea, completando las condiciones de otorgamiento, y asumiendo toda la gestión incluyendo la tramitación y la concesión. En las competencias ejecutivas, corresponderá a la Comunidad Autónoma la gestión de las subvenciones territorializables, que incluye su tramitación y concesión».

Se trata de cláusulas, más o menos precisas, que tratan de codificar la jurisprudencia del Tribunal Constitucional en lo que se refiere a la gestión de los fondos europeos. En su sentencia n ${ }^{\circ} 31 / 2010$, de 28 de junio, sobre el Estatuto catalán, el Tribunal Constitucional sólo puntualiza en relación con su artículo 210 sobre la Comisión Mixta de Asuntos Económicos y Fiscales Estado-Generalitat: «... el porcentaje de participación de Cataluña en la distribución territorial de los fondos estructurales europeos [letra d)] son aspectos, todos ellos, que guardan directa conexión con lo establecido en los arts. 157.1 y 3 y $158 \mathrm{CE}$, debiendo ser regulados por el Estado con referencia al marco específico de coordinación y colaboración entre aquél y las Comunidades Autónomas que la Constitución ha previsto, por tratarse de cuestiones que afectan a todas las Comunidades Autónomas. Por tanto, las letras del apartado 2 se limitan a fijar un marco bilateral de negociación y de formalización de acuerdos que complementa, sin cuestionarlo, el procedimiento general de toma de decisiones en el seno del órgano multilateral de colaboración y coordinación [...] en el art. 210 EAC las funciones de cooperación de la Comisión Mixta de Asuntos Económicos y Fiscales Estado-Generalitat no excluyen ni limitan la capacidad de las instituciones y organismos de carácter multilateral en materia de financiación autonómica, no afectan a la reserva de Ley Orgánica prevista en el art. 157.3 CE, ni sustituyen, impiden o menoscaban el libre y pleno ejercicio por el Estado de sus propias competencias» (FJ 135).

\section{CONGLUSIÓN}

En la integración europea las Regiones han pasado de ser una mera referencia geográfica a constituirse en uno de los actores más visibles de la Unión. Sin tener el protagonismo de los Estados miembros, existen ámbitos de integración, como la política regional, la cultura o las redes transeuropeas, que no se entenderían sin la implicación de las Regiones como nivel de gobierno que debe participar en la integración europea. En estos casos y sólo por razones de sim- 
plificar el funcionamiento de la Unión Europea y las relaciones institucionales se siguen manteniendo algunas exclusiones manifiestas de la participación regional ante las instituciones europeas. Por eso me parece esclarecedor el juicio de Mariscal Berástegui que, al referirse a los efectos del Tratado de Lisboa, señala: «No será la Europa de las regiones, pero hay que tomarse en serio a Europa con sus regiones, no sólo para que reciban, sino para que aporten, no como coartada para superar el propio nivel, sino para que contribuyan activamente desde él a la Europa diversa y una de todos» ${ }^{27}$.

Desde el punto de vista institucional, la participación de las Comunidades Autónomas en el proceso de toma de decisiones en la Unión Europea no deja de ser discreta. Sin embargo, son muy relevantes los cauces abiertos por el Estado autonómico a la participación en los distintos niveles del Consejo de la Unión Europea, con un consejero autonómico en la Representación Permanente en Bruselas y con la participación en alguno de los Consejos de Ministros. Pero en ningún caso pueden olvidar el Estado ni las Comunidades Autónomas la necesaria unidad de acción hacia el exterior, aun cuando sea en el seno de la Unión Europea; la proverbial estabilidad del Gobierno de la Nación ha permitido que, por ejemplo en el Consejo Europeo, hayan participado hasta ahora y durante más de dos décadas únicamente tres españoles: González, Aznar y Rodríguez Zapatero, con una razonable media, a efectos de gobernanza de más de ocho años. Factor de estabilidad y de representatividad en la Unión Europea que no puede ser minusvalorada desde la perspectiva de los intereses tanto del Estado como de las Comunidades Autónomas, es decir, los intereses de España.

Asimismo, la implicación y la interacción de los funcionarios autonómicos con los eurofuncionarios y los de otros Estados miembros a través de la participación en los distintos comités de la Comisión y en los grupos de trabajo del Consejo y, en fin, con la Consejería Autonómica en la Representación Permanente de España ante la Unión Europea así como en las Delegaciones de Representación Autonómica en Bruselas constituyen vías importantes para asegurar una participación de las Comunidades Autónomas en los asuntos europeos.

Al mismo tiempo, el Protocolo sobre la subsidiariedad abre desde el 1 de diciembre de 2009 nuevos cauces de participación de los Parlamentos autonómi-

27 Nicolás MARISCAL BERÁSTEGUI, Más allá de Lisboa: Horizontes europeos, Tecnos, Madrid, 2010, p. 240. 
cos, a través de las Cortes Generales, y también por medio del Comité de las Regiones, en el control de la adopción de decisiones en la Unión Europea.

En cuanto se refiere a la aplicación normativa del Derecho de la Unión Europea, las Comunidades Autónomas han desempeñado un escaso papel, probablemente por falta de desarrollo institucional pero también por la razonable eficacia mostrada en este ámbito por los órganos normativos del Estado: las Cortes Generales y el Gobierno de la Nación.

En cambio, las Comunidades Autónomas se han erigido en las Administraciones 'periféricas' de la Unión Europea, en términos de Ortega Álvarez, para la gestión de las políticas más sobresalientes y, especialmente, cuando tales políticas tienen que canalizar fondos europeos. Sin perjuicio de algunas precisas particularidades de la cooperación bilateral entre el Estado y cada una de las Comunidades Autónomas, resulta manifiesto que en el ámbito europeo sólo es posible llevar a cabo una cooperación multilateral entre todas las Comunidades Autónomas y el Estado central.

Así pues, el proceso de integración europea ha actuado como marco del desarrollo autonómico español y, a mi juicio, ha sido un contexto que ha permitido limar las asperezas de la lucha competencial entre el Estado y las Comunidades Autónomas e incluso en muchos casos e indirectamente ha inoculado un cierto grado de cordura en momentos clave del proceso político: desde una atención mayor a la unidad 'europea' de mercado, hasta una más apropiada revalorización de elementos culturales diferenciadores. No obstante, sería preciso que se potenciase la coordinación y la colaboración entre las instancias estatal y autonómicas, hacia arriba, en este caso Europa, pero también hacia abajo, con la mirada puesta en las necesidades locales.

El Parlamento español se ha convertido en gran medida en un órgano de ejecución normativa de la Unión Europea donde muy escasamente se planifica y programa la agenda y donde los debates sobre las cuestiones europeas son dirigidos sin apenas oposición ni debate por el Gobierno de la Nación, cuyo presidente da cuenta de los extraordinarios éxitos cosechados en sus negociaciones al más alto nivel con los demás líderes europeos.

El principio dispositivo ha producido una rica variedad de cláusulas europeas: cada Comunidad Autónoma ha buscado su propia vía hacia Europa, trazando líneas y marcas precisas pero que, en realidad, dependen de la regulación del Derecho de la Unión y del Derecho estatal y constituyen una codificación de 
la jurisprudencia constitucional y de la práctica llevada a cabo en las tres décadas de participación autonómica en la integración europea.

El principio imitativo también permiten ver la filiación de cada Estatuto y la correlación de fuerzas autonómicas y estatales. Ciertamente, unos Estatutos fueron elaborados con importantes fuerzas no controladas por los partidos mayoritarios de ámbito estatal lo que significó en el caso del Proyecto de Estatuto vasco que fuese abortado en las Cortes Generales y en el supuesto del Estatuto catalán que sus aspiraciones fuesen rebajadas por el Tribunal Constitucional dejando, sin embargo y de manera significativa, incólumes las cláusulas europeas. No obstante, en los nuevos Estatutos se observa en el legislador estatutario la estrategia del 'atrápalotodo' proyectado en el blindaje del Estatuto catalán o en la cláusula Camps del Estatuto valenciano ${ }^{28}$.

Probablemente, estas estrategias de emulación y de plenitud no sean lo mejor para asegurar una participación provechosa en la Unión Europea dado que estamos abocados a una colaboración leal entre los distintos niveles de gobierno -europeo, estatal, regional y local-y a un ejercicio de las competencias conforme a la subsidiariedad y a la gobernanza. Colaboración, subsidiariedad y gobernanza que no parecen haber calado en la construcción de la Unión Europea pero tampoco estos principios estructurales han dado todos sus frutos en el Estado autonómico español.

${ }^{28}$ La Disposición Adicional Segunda del Estatuto valenciano reformado señala: «1. Cualquier modificación de la legislación del Estado que, con carácter general y en el ámbito nacional, implique una ampliación de las competencias de las Comunidades Autónomas será de aplicación a la Comunitat Valenciana, considerándose ampliadas en esos mismos términos sus competencias. 2. La Comunitat Valenciana velará por que el nivel de autogobierno establecido en el presente Estatuto sea actualizado en términos de igualdad con las demás Comunidades Autónomas. 3. A este efecto, cualquier ampliación de las competencias de las Comunidades Autónomas que no estén asumidas en el presente Estatuto o no le hayan sido atribuidas, transferidas o delegadas a la Comunitat Valenciana con anterioridad obligará, en su caso, a las instituciones de autogobierno legitimadas a promover las correspondientes iniciativas para dicha actualización». 